\title{
Project scheduling and forecasting by laws of physical movement
}

\author{
Morteza Bagherpour $^{a^{*}}$, Hamidreza Mardimamaqania ${ }^{a}$, Amirhossein Fallahdizcheh ${ }^{\text {a }}$ and Her- \\ man Steyn
}

${ }^{a}$ School of industrial engineering, Iran University of Science and Technology, Tehran, Iran ${ }^{b}$ Professor of project management, University of Pretoria, Pretoria, South Africa

\section{CH R O N I C L E}

Article history:

Received: October 242018

Received in revised format: No-

vember 152018

Accepted: January 22019

Available online:

January 42019

Keywords:

Project progress

Physics rules

Equation path

Final duration

Schedule performance

Cost performance

\section{A B S T R A C T}

\begin{abstract}
Measuring actual project progress and comparing it with the planned time schedule is essential in controlling of a project. The outcome of the latter follows the s-curve diagram, which compares actual progress with the planned amount and finally analyzing any gap between them to draw directions for project scheduling. However, final duration of the project cannot be either estimated or predicted through conventional methods. The new method, using Rules of kinematics, can calculate the final duration of the project. This novel approach is successfully implemented on a construction project. The first objective in new method is forecasting final duration of the project, finding equation path and draw a new s-curve diagram for actual status during the execution process. The second objective is to evaluate schedule performance of the project and report the status of the project at each period which is a useful tool for managers.
\end{abstract}

C 2019 by the authors; licensee Growing Science, Canada.

\section{Introduction}

\subsection{Project management and cost management}

Project management is the process of planning and directing a project undertaken in the format of specific cost, time and acceptable level of quality moving toward the specific results. Project management normally includes planning, organizing; supervision and guidance implementation of the project and tries to use specific resources in order to reach to the defined objectives in terms of time and cost. Project management includes five Process groups that are mentioned below (PMBOK guideline).
1) Initiation
2)Planning
3)Production or execution
4)Monitoring and controlling
5)Closing

Project cost management is a process for planning, estimating, budget allocation, and controlling the cost of the project from initiating to the end of the project. Four processes exist in project cost management that are mentioned below:
1)Planning Cost Management
2)Estimating Costs
3)Determining Budget
4)Controlling Cost

* Corresponding author.

E-mail address: mortezabagherpour@gmail.com (M. Bagherpour)

(C) 2019 by the authors; licensee Growing Science, Canada

doi: $10.5267 /$ j.jpm.2019.1.001 
A useful method for project cost management is earned value management (EVM) method which monitors both schedule performance index and cost performance index for a project.

\subsection{Measuring project progress}

Project progress measurement is the best-known aspect of project control. It shows the percentage of the work done using two elements. With comparison with the actual progress and the planned progress, the relation between planned status and actual status is normally determined. Furthermore, the s-curve plan depicts a summary of the project including the last know status of the project. In a project, there are some activities and for each activity, there is an assigned weight value. This weight value (factor) may be related to activity cost or activity time percentage or a new method for measuring can be employed. It is common that the cost of the activity determines the weight value in project management systems as below given.

$$
\mathrm{w}_{\mathrm{i}}=\frac{\text { the cost of this activity }}{\text { total cost of project }}
$$

$\mathrm{w}_{\mathrm{i}}$ Is the weight value for activity

For measuring the percentage of the project progress, this relation holds:

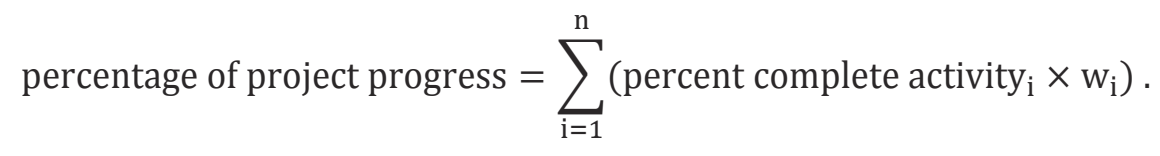

The (S-curve-plan) shows cumulative project progress at all periods. In addition, projects have a slow progress pace at the beginning of project and high project progress pace in the middle of project and slow project progress pace at the end of the project due to normal distribution function.

S-curve diagram shows actual progress and planned progress and compares them and also shows delays or antecedence.

The deviation between the plan and the actual status can be calculated using this relation:

$$
\text { Deviation }=\text { actual progress }- \text { planned progress . }
$$

If the deviation is negative, it means delay, and if it is positive, it means the project is ahead of schedule.

\subsection{Physics' basic principles}

In the mechanical physics, a moving object is a crucial element which moves in the Three-dimensional space and it has velocity and Acceleration. Assume that the moving object, moves on Axis length $(\mathrm{X})$ and it does not show any movement in the other arises. Displacement of the moving object in different periods is " $\Delta \mathrm{X}$ ", and Time difference between different periods is " $\Delta \mathrm{T}$ ". With these two assumptions, the velocity and acceleration can be calculated as follow:

$$
\begin{aligned}
& \mathrm{v}=\frac{\Delta \mathrm{X}}{\Delta \mathrm{T}}(\mathrm{M} / \mathrm{S}) \\
& \mathrm{a}=\frac{\Delta \mathrm{v}}{\Delta \mathrm{T}}\left(\mathrm{M} / \mathrm{S}^{2}\right)
\end{aligned}
$$

where $v$ shows velocity, $a$ is acceleration, $M$ is the unit of distance in meters and $S$ represents the unit of time in seconds. For forecasting the location of the moving object, these following relations are true, if the moving object has fixed acceleration movement.

$$
\begin{aligned}
& \Delta \mathrm{x}=\overline{\mathrm{v}} \mathrm{t} \\
& \Delta \mathrm{x}=\frac{1}{2} \mathrm{at}^{2}+\mathrm{v}_{0} \mathrm{t} \\
& \mathrm{v}=\mathrm{at}+\mathrm{v}_{0}
\end{aligned}
$$




$$
\begin{aligned}
& \bar{a}=\frac{\Delta v}{t} \\
& x=v t+x_{0}
\end{aligned}
$$

If the moving object is not moving with fixed acceleration, Differential Equations solve the problem. And the following relations apply:

$$
\begin{aligned}
& \mathrm{a}=\frac{\mathrm{dv}}{\mathrm{dt}}, \mathrm{v}=\int \mathrm{adt} \\
& \mathrm{v}=\frac{\mathrm{dx}}{\mathrm{dt}}, \mathrm{x}=\int \mathrm{vdt} \\
& \mathrm{a}=\frac{\mathrm{d}^{2} \mathrm{x}}{\mathrm{dt}^{2}}, \mathrm{x}=\iint \mathrm{adt}^{2}
\end{aligned}
$$

By comparing velocity and acceleration and multiplying them together, the following results will be obtained:

1) If $\mathrm{v}>0$ \& $\mathrm{a}>0$ the moving object movement has been fasten.

2) If $\mathrm{v}>0 \quad \& \mathrm{a}<0$ the moving object movement has been slowed.

3) If $\mathrm{v}<0 \quad \& \mathrm{a}>0$ the moving object movement has been slowed.

4) If $v<0 \& a<0$ the moving object movement has been fasten.

To analyze the moving object movement, there are three diagrams as follow:

1) Space-time graph which depicts moving object location in different times and periods

2) Speed-time graph which depicts moving object speed in different times and periods

3) Acceleration - time graph which depicts moving object acceleration in different times and periods

\subsection{Physics and project final duration literature}

Physics is a fundamental science and is in well integrated with other branches of natural sciences, such as chemistry, biology, astronomy, geology, psychology and other sciences, and in some cases, other sciences are developed by the implementation of the laws of physics. As an instance, a branch of chemistry, known as statistical mechanics which is improved by physics. Related studies in project progress concentrated on its development and for predicting final duration of project progress have been conducted.

Hosseinian and Reinschmidt (2015) predicted project final duration, which is the time span used to finish the progress of the project by the means of Bayesian inference. Bayesian inference is referred to as a strong probability-based approach for providing the final outcome of the progress considering the previous performance of the project. Based on the results, the most accurate approach is Deal Gompertz function. Warburton and Cioffi (2016) discussed earned schedule formula for linear approximation, which in some cases has worked with nonlinear equations ones as well, and the circumstances in which both correct \& incorrect results were provided, has been discussed using some small proportion examples which resemble real-nonlinear data of projects, the authentication and precision of model has been elaborated. Caron et al. (2016) and Caron and Ruggeri (2016) determined to enhance the prediction process by developing Bayesian approach. They developed a model in which three knowledge resources known as expert judgments, received data from the previously conducted projects and the current circumstance of ongoing project are combined. The outcome of the new model puts forth the idea that forecasting accuracy has been improved in comparison with previous model. Kim and Reinschmidt (2009) presented modern probability based forecasting method for schedule performance control \& risk management of the ongoing projects in their study. According to Bayesian inference and beta distribution, the Bayesian beta s- curve has been discussed. The implementation of B.BM resulted in providing safety margin for the prediction, which come up with the chance to specify the range of outcomes $\&$ the probability of success. Yousefi (2018) estimated the final budget of the project by using the time value of money, delay in 
employee payment and contractor cash flow in various parts of the construction project by considering different time of the project. Vandevoorde and Vanhoucke (2006) initially studied the comparison of the earned value performance indication, SV \& SPI with the newly presented earned schedule performance indicators, SV $(+) \&$ SPI $(+)$ in their paper. Vanhoucke \& Vandevoorde, 2007) used high degrees of simulation in order to control the level of uncertainty in the project, the impact made by project network structure on the precision of predictions and the specific time when accurate and reliable results are provided by the EV-based measures. The basis of their opinions was on specific project settings with all the activities and precedence relations specified and without considering unpredictable events and unknown relations among various actions that might trigger unexpected impact in different aspects of the project. Pewdum et al. (2009) introduced a model to forecast the budget and the duration of a sample highway construction project during its building time. Their study was conducted by gathering other highway construction projects data and by analyzing them in order to find different attributes effecting the final budget and duration in advance, based on the principle of Artificial Neural Network (ANN). Their study results were advantageous for implementing in highway project in order to forecast final budget and duration of the project. Li et al. (2006) in their paper developed a forecasting approach for prediction of potential cost overruns and schedule delay for construction projects. The effect of numerous factors, referred to as indicators on project cost overruns and schedule delay has been discussed in the paper using fuzzy logic. Bagherpour et al. (2016) developed a new methodology for financial system of the project, based on the rules and regulations of mechanical equilibrium of a beam. They studied the new method and the outcome was successfully effective, which enhanced the standard project cost management system. Narbaev and De Marco (2014) in their paper developed a new cost estimation at completion method (CEA) for a project which is still in progress. The presented model is based on a modified index-based formula in order to predict expected cost for the remaining tasks in the project using the Gompertz growth model via nonlinear regression on curve fitting. Additionally, the new equation elaborates on the schedule progress as a performance factor of cost. For achieving this goal, an earned schedule- based factor is added up into its equation, specifying regarded duration at completion. Elshaer (2013) followed two main targets in his study. At the beginning, he observed the effect of the activity's sensitivity information on the prediction accuracy of the Earned schedule method (ESM). Moreover, the second purpose was to claim in normal circumstances, the project performance indicator presented by ESM at higher work breakdown structure is trustful.

This study presented in this paper is novel and there are no researches related to this concept in the literature.

\section{Using physics rules in project progress management}

\subsection{Problem statement}

In the project process management, the deviation between actual progress and planned progress is calculated. In addition, S-curve diagram is drawn to compare them, and report the project progress. Using this approach, the final duration of the project cannot be calculated. However, some methods are being improved, but they are so complex and they are hard to be implemented. In new method this problem has been solved, in other words, the new method is fast, accurate and easy to use.

\subsection{Problem modeling}

Consider the project as the moving object and it moves just in length axis. Supposing that, progress between two periods is $(\Delta \mathrm{X})$ and the time difference between two periods is $(\Delta \mathrm{T})$, so the velocity and the acceleration of the project will be calculated as below:

Velocity of project progress $=\Delta \mathrm{X} / \Delta \mathrm{T}$

Acceleration of project progress $=\Delta \mathrm{v} / \Delta \mathrm{T}$ 
According to nature of the project, the velocity is always positive and the acceleration can be either negative or positive. Multi wise function is used and the project is divided into various parts. The project can be divided into several parts according to its nature. In this study, the project is divided into four parts. Here, there is a similarity between part 1 and part 4 and also between part2 and part3. Part1 and part4 are similar because the project progress in early and late stage is slow and have similar changes. Part2 and part3 are similar to each other because in the middle of the project, progress is fast and changes are similar.

In below, different parts of project are defined as follow:

\section{Part1: $0 \%$ to $10 \%$ of project progress}

Part2: $10 \%$ to $50 \%$ of project progress

\section{Part3: $50 \%$ to $90 \%$ of project progress}

Part4: $90 \%$ to $100 \%$ of project progress

Furthermore, several scenarios are considered for the future of the project and mathematical expectation are implemented for better prediction.

\section{The propose method}

\subsection{Predicting project progress}

In this method, the movement of the project has been considered as constant and the acceleration is therefore zero. Speed in this method is constant, and can be calculated between the periods, as follow:

$$
\mathrm{v}_{\mathrm{i}}=\frac{\text { project progress }_{\mathrm{t}_{2}}-\text { project progress }}{\mathrm{t}_{1}},
$$

where $V_{i}$ is the velocity in every period and $n$ is the number of periods. For every part of the project, average velocity is calculated and with the average velocity, the equation path of the project progress is considered as follow:

$$
\overline{\mathrm{v}}_{\mathrm{n}}=\frac{\sum_{\mathrm{n}=\mathrm{j}}^{\mathrm{n}=\mathrm{i}} \mathrm{v}_{\mathrm{n}}}{\mathrm{i}-\mathrm{j}}
$$

where $\bar{v}_{\mathrm{n}}$ is the average velocity at each period. Then for finding equation path in every part, the following relationship holds,

$$
\mathrm{x}_{\mathrm{n}}=\overline{\mathrm{v}}_{\mathrm{n}} \mathrm{t}+\mathrm{x}_{0}
$$

When there is a $40 \%$ progress in the actual, the prediction using this method would be more precise, and it is possible to calculate the final duration of the project. Different scenarios are considered for the future of the project and mathematical expectation is used for better prediction. The following mathematical expectation assists us to calculate velocity for future under the several risks.

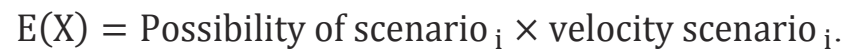

In the past, it is assumed that average velocity in part1 and part 4 are equal and also for part 2 and part3. To improve this assumption, data from planned progress are used and $\mathrm{E}(\mathrm{X}), \alpha$ and $\beta$ indexes are founded and then average velocity is calculated as follow:

$$
\begin{aligned}
& \overline{\mathrm{v}}_{\text {part4 }}=\alpha \times \mathrm{E}(\mathrm{X}) \times \overline{\mathrm{v}}_{\text {part1 }} \\
& \bar{v}_{\text {part } 3}=\beta \times E(X) \times \bar{v}_{\text {part } 2}
\end{aligned}
$$

For finding $\alpha$ and $\beta$ indexes planned progress is used and these relations hold,

$$
\begin{aligned}
& \alpha=\frac{\bar{v}_{\text {part } 4}}{\bar{v}_{\text {part } 1}} \\
& \beta=\frac{\bar{v}_{\text {part } 3}}{\bar{v}_{\text {part } 2}}
\end{aligned}
$$


At the end of the project we have $\mathrm{x}=100$ and the time can be calculated with $\mathrm{x}=\mathrm{vt}+x_{0}$ equation. $x_{0}=0$ in the first part, because in the first-day project progress is zero. It should be noted that at each part of the project, time follows the relationship of $x=v \times t+x_{0}$, starting from zero and $x_{0}$ equals to project progress up to now. The main application of this section is so help managers because by the implementation of this method managers can predict the future of the project, and also, they know when the project will be finished. Furthermore, by this method, new s-curve of the project can be drawn, which is based on actual progress. In other words, they can compare actual with actual and it's a novel approach.

\subsection{Checking the Current trends of project progress}

The velocity is always positive and the acceleration can be negative or positive, by comparing these indexes new index (VI) can be developed. By using the new index we evaluate the current trends of project progress as follow:

$\checkmark$ If velocity $>0$, acceleration $<0$ the project progress is slow.

$\checkmark$ If velocity $>0$, acceleration $>0$ the project progress is fast.

By comparing the current trends of project progress in actual state or planned state the gap can be detected and project status is analyzed.

For every period, comment could be stated whether the delays are scheduled delays or not. For example, if in plan and actual the $(\mathrm{VI}<0)$, the delay is scheduled.

\subsection{Compare the actual progress with planned progress}

By comparing the percent of the project progress and the actual progress and the planned progress no comments can be stated about the work done in the last period. Because maybe the progress has been slow during the last period but the percent of the actual progress is more than planned progress in total. This is elaborated as the project is ahead of the schedule and does not show the project progress has become slow during the last period and vice versa. For the comment about project progress between two periods, the velocity of progress should be calculated. By comparing the actual and planned indexes comment could be mentioned about how the job is progressing. There are two indexes (PVI, PAI) as follow:

$$
\begin{aligned}
\mathrm{PVI}_{\mathrm{i}} \text { (Project velocity index) }=\frac{\text { actual velocity }}{\text { planned velocity }} & \\
& \checkmark \quad \text { If }_{\mathrm{PVI}}>1 \text { the actual progress is faster than plan in this period } \\
& \checkmark \quad \text { If }^{\mathrm{PVI}_{\mathrm{i}}}<1 \text { the actual progress is slower than plan in this period }
\end{aligned}
$$

The success rate of work index (SRWI) is another index for comparing the actual progress and the planned progress in every period, and can be calculate as follow:

$$
\mathrm{SRWI}_{\mathrm{i}}=\mathrm{PVI}_{\mathrm{i}} \times 100
$$

Under ideal conditions we have $\mathrm{SRWI}_{\mathrm{i}}=100 \%$ but the real conditions are impossible. For checking this index these relations apply:

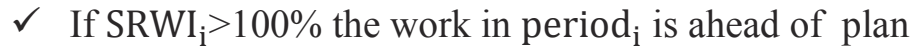

$\checkmark$ If SRWI $_{\mathrm{i}}=100 \%$ the work in period ${ }_{\mathrm{i}}$ is on plan

$\checkmark \quad$ If $\mathrm{SRWI}_{\mathrm{i}}<100 \%$ the work in period $\mathrm{i}_{\mathrm{i}}$ is Behind plan

Managers by using models in 2nd and 3rd sections can measure the performance evaluation of the project and can prepare reports for every period. Until now an important problem in reporting project progress has been comparing actual progress with planned progress in the project. By using SRWI and VI indexes managers can report the status of the project in every period, not only the project in total. 


\subsection{Algorithms}

Algorithms for this method are drawn for the better understanding of the new model. Algorithm number one shows the process to predict the future of the project progress and to calculate the final duration of it. Algorithm number two indicates the process of checking the current trends of the project progress and finally, algorithm number three shows the process of comparing the actual progress with the planned progress.

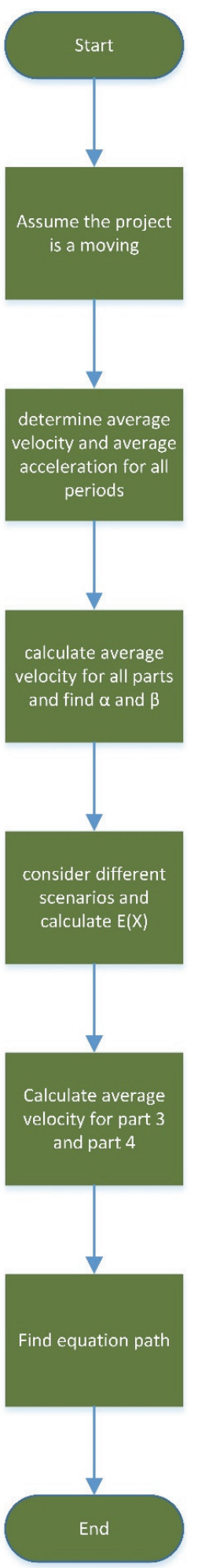

Fig. 1. Algorithm number one
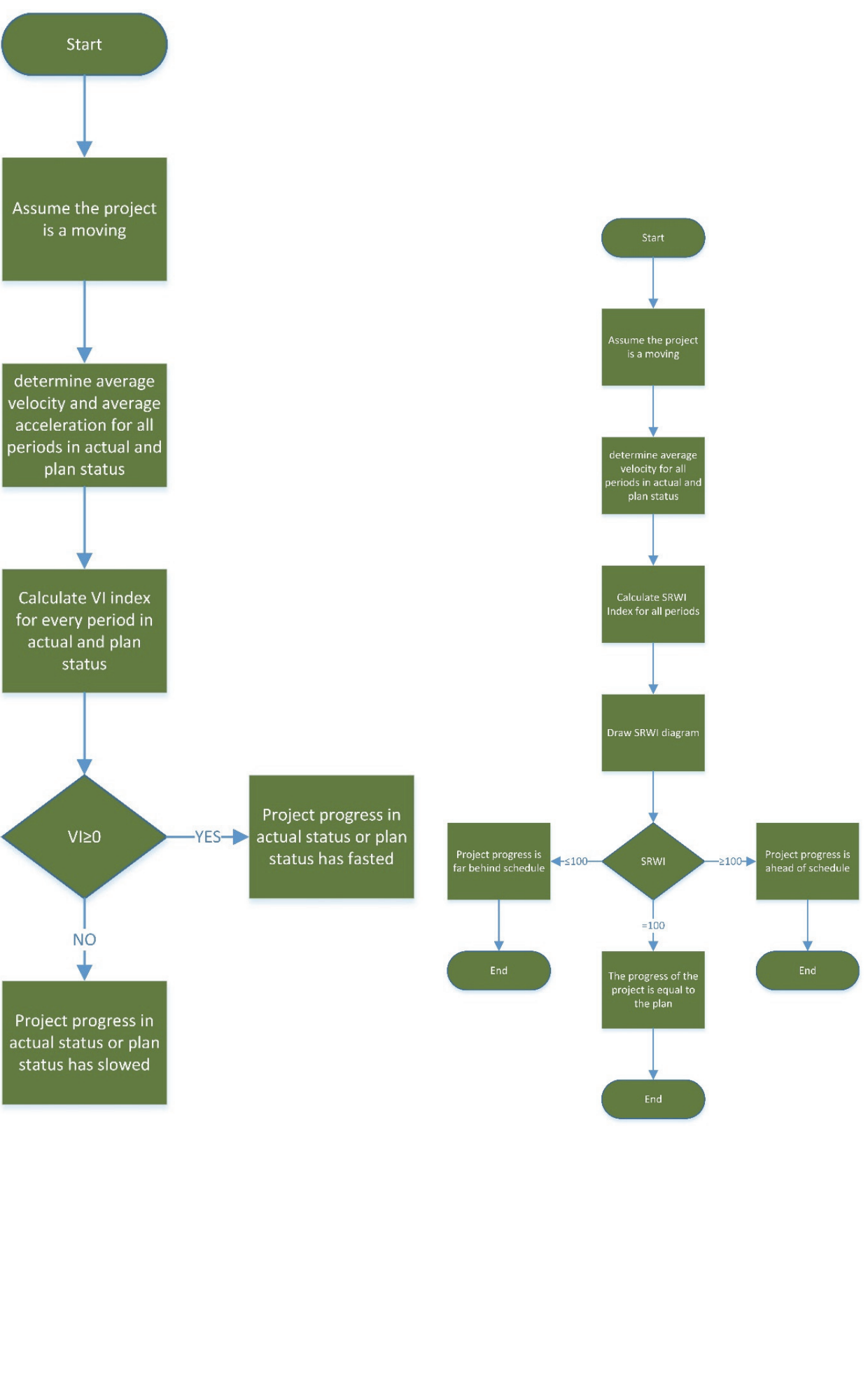

Fig. 2. Algorithm number two

Fig. 3. Algorithm number 3 


\section{Case study and results}

By using a case study, new method is examined. Progress data is collected in actual and planned status. In the plan, the project will be finished in 18 months. Supposing that the project is at its 9th month in actual status, and the final duration is required to be predict. Information about actual and planned status has been given in next tables.

\section{Table 1}

Planned status

\begin{tabular}{cccc}
\hline Mounts & Planned Progress & Planned Velocity & 0 \\
\hline 0 & 0 & 2 & 0 \\
1 & 2 & 3 & 2 \\
2 & 5 & 5 & 1 \\
3 & 10 & 5 & 0 \\
4 & 15 & 7 & 2 \\
5 & 22 & 8 \\
6 & 30 & 9 \\
7 & 39 & 11 \\
8 & 50 & 10 \\
9 & 60 & 8 & 1 \\
10 & 68 & 7 & 2 \\
11 & 75 & 7 & -1 \\
12 & 82 & 6 \\
13 & 88 & 4 \\
14 & 92 & 3 & -2 \\
15 & 95 & 2 & 0 \\
16 & 97 & 2 & -1 \\
17 & 99 & 1 & -1 \\
18 & 100 & -1 & 0 \\
\hline
\end{tabular}

\section{Table 2}

Actual status

\begin{tabular}{|c|c|c|c|}
\hline Mounts & Actual Progress & Actual Velocity & Actual Acceleration \\
\hline 0 & 0 & 0 & 0 \\
\hline 1 & 2 & 2 & 2 \\
\hline 2 & 4 & 2 & 0 \\
\hline 3 & 7 & 3 & 1 \\
\hline 4 & 11 & 4 & 1 \\
\hline 5 & 17 & 6 & 2 \\
\hline 6 & 23 & 6 & 0 \\
\hline 7 & 30 & 7 & 1 \\
\hline 8 & 38 & 8 & 1 \\
\hline 9 & 49 & 11 & 3 \\
\hline 10 & 55.65 & 6.65 & -4.35 \\
\hline 11 & 62.3 & 6.65 & 0 \\
\hline 12 & 68.95 & 6.65 & 0 \\
\hline 13 & 75.6 & 6.65 & 0 \\
\hline 14 & 82.25 & 6.65 & 0 \\
\hline 15 & 88.9 & 6.65 & 0 \\
\hline 16 & 90.66 & 1.76 & -4.89 \\
\hline 17 & 92.42 & 1.76 & 0 \\
\hline 18 & 94.18 & 1.76 & 0 \\
\hline 19 & 95.94 & 1.76 & 0 \\
\hline 20 & 97.7 & 1.76 & 0 \\
\hline 21 & 99.46 & 1.76 & 0 \\
\hline 22 & 101.22 & 1.76 & 0 \\
\hline
\end{tabular}

In the first step, the equation path is calculated for planned status by using physics rules. The project is broken down into four parts, next it is assumed that the acceleration in every part is zero. Next, the average speed is calculated for every part and find the equation path as follow: 
Table 3

Calculations

\begin{tabular}{ccccc}
\hline Part name & Average velocity & mounts & time & Equation path \\
\hline Starting part & 2.5 & $1-3$ & $1-4$ & $x=2.5 t$ \\
Middle part1 & 8 & $4-8$ & $1-5$ & $x=8 t+10$ \\
Middle part2 & 7 & $9-13$ & $1-4$ & $x=7 t+50$ \\
Finishing part & 2 & $14-18$ & $1-6$ & $x=2 t+88$ \\
\hline & & & \\
$\bar{v}=\frac{\text { project progress }_{t_{2}} \text {-project progress }_{t_{1}}}{t_{2}-t_{1}}$ & $\bar{v}_{1}=\frac{10-0}{4}=2.5, x_{0}=0$ & $\bar{v}_{2}=8, x_{0}=10$ & \\
$\bar{v}_{3}=7 x_{0}=50$ & $\bar{v}_{4}=2 x_{0}=88$ & $x=v t+x_{0}$ &
\end{tabular}

Finally, this diagram is drawn and it depicts that the equation path is very similar to the real data.

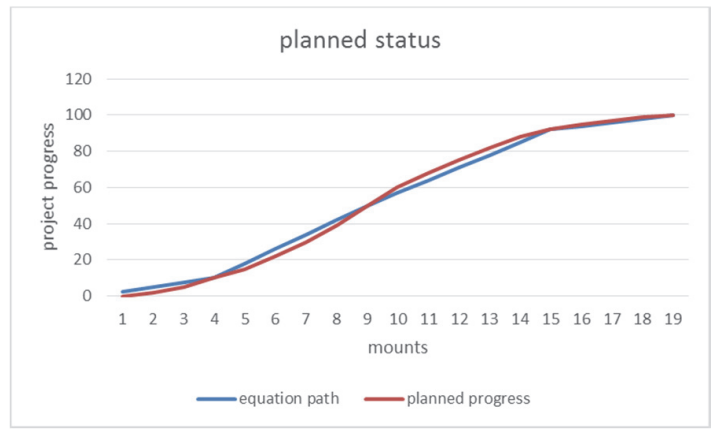

Fig. 4. Planned status

In the second step, at the 9th month in the actual status, and the future of the project and find final duration is supposed to be predicted. According to the current conditions, there are five scenarios as follow:

Table4

Scenario building

\begin{tabular}{ccc}
\hline Scenario name & Possibility & Project progress \\
\hline A & 0.1 & $15 \%$ faster than normal \\
B & 0.17 & $5 \%$ faster than normal \\
C & 0.53 & Normal \\
D & 0.12 & $8 \%$ slower than normal \\
E & 0.08 & $17 \%$ slower than normal \\
\hline
\end{tabular}

In this case, no data is available about the future, and future must be forecasted by using past information in other words, plan data.

Table5

Forecasting future

\begin{tabular}{ccccc}
\hline Part name & Average velocity & mounts & $\mathrm{t}$ & Prediction path \\
\hline Starting part & 2.2 & $1-4$ & & \\
Middle part1 & 7.6 & $5-9$ & & \\
Middle part2 & 5.78 & $10-15$ & $1-6$ & $x_{3}=6.65 t+49$ \\
Finishing part & 0.89 & $16-21$ & $1-6$ & $x_{4}=1.76 t+88.9$ \\
\hline
\end{tabular}

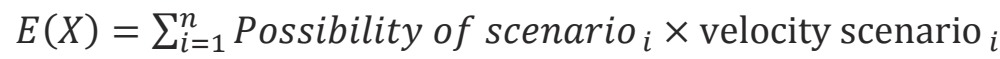

$E(X)=(0.1 \times 1.15)+(0.17 \times 1.05)+(0.53 \times 1)+(0.12 \times 0.92)+(0.08 \times 0.83)=1.0003$ 
Now $\alpha$ and $\beta$ indexes are calculated as follow:

$\alpha=\frac{\bar{v}_{\text {part } 4}}{\bar{v}_{\text {part } 1}}=\frac{2}{2.5}=0.8$

$\beta=\frac{\bar{v}_{\text {part } 3}}{\bar{v}_{\text {part } 2}}=\frac{7}{8}=0.875$

Then average velocity is calculated for part3 and part4 as follow:

$\bar{v}_{\text {part } 4}=\alpha \times E(X) \times \bar{v}_{\text {part } 1}=0.8 \times 1.0003 \times 2.2=1.76$

$\bar{v}_{\text {part } 3}=\beta \times E(X) \times \bar{v}_{\text {part } 2}=0.875 \times 1.0003 \times 7.6=6.65$

Finally, prediction path easily can be calculated as follow:

$\mathrm{x}_{\mathrm{n}}=\overline{\mathrm{v}}_{\mathrm{n}} \mathrm{t}+\mathrm{x}_{0}$

$x_{3}=6.65 t+49$

for finding part 4 it is supposed that $x_{3}=90$ then time is calculated and $\mathrm{x}_{0}$ for part 4 as follow:

$90=6.65 \mathrm{t}+49$ thus $\mathrm{t}=6$

So part4 starts at 16th month and equation path is calculated for this part.

$x_{4}=1.76 t+88.9$

Now s-curve plan is drawn for showing the results.

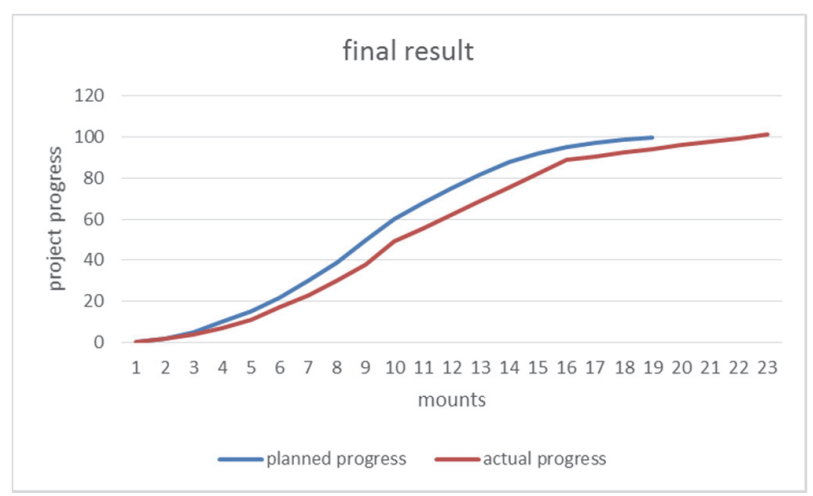

Fig. 5. Final result

It is predicted that the project shall be finished in 21 months also the project progress is determined for every month in the future.

In Third step, velocity and acceleration for every period is calculated, then by comparing them; it is easy to realize that which months project progress has been slowed, and which months has been fasted. In the top table VI index is calculated, which are green shows that VI index is positive and project progress in actual status or planned status has been fasted and vice versa. Remember that velocity is always positive and just acceleration sign is important for the obtained VI index.

In final step SRWI index is calculated for every period, this index is very useful for commenting on work in every month according to the plan.

Suppose being at the 8 th month, calculate SRWI index can be calculated as follow:

$\mathrm{PVI}_{8}($ Project velocity index $)=\frac{\text { actual velocit } y_{8}}{\text { planned velocity }}=\frac{8}{11}=0.73$

$S R W I_{8}=\mathrm{PVI}_{8} \times 100=73 \%$ 
It should be noted that SRWI can be calculated until the 9th month.

And SRWI index is calculated for every month and the SRWI index diagram is drawn as follow:

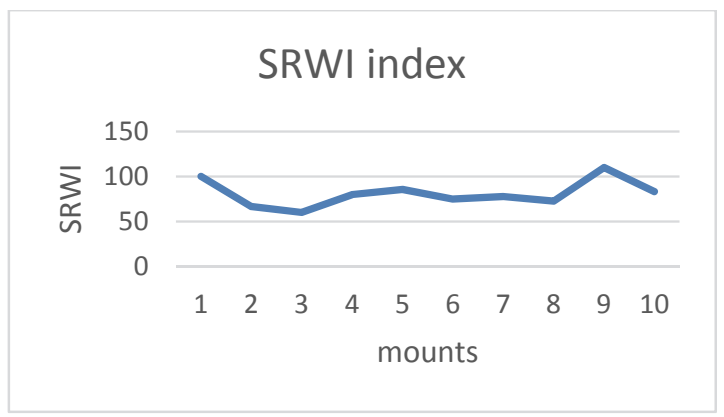

Fig. 6. SRWI index

According Fig. 6, the performance evaluation of the project progress can be executed properly and discussed.

\section{Finding and discussion}

When the project is in the middle of progress, with this new method engineers can predict the final duration of the project by using these rules. This method uses planned progress data and the past performance of the project in actual status to predict future. Another application is the performance evaluation of project progress in actual status. SRWI index shows this concept and ideally when it is $100 \%$, managers can comment that project progress is on the plan.

When the project progress has heavy fluctuations, this method is pretty limited. In other words, this method is not useful for this case, because predicted path and the accrual progress become distinctly different, so, the prediction would be in efficient. Unforeseen factors cause this problem, such as wars, natural disasters, financial problems and other reasons.

The scenarios predicted have high impact on the future. If these scenarios are false, the prediction of future may be different with actual. So, it is necessary to forecast scenarios and their probability accurately because $\mathrm{E}(\mathrm{X})$ has the direct effect in the amount of average velocity in part 3 and part4.

It is obvious that part 1 and part 4 also part 2 and part 3 are similar. So, use part 1 can be used for predicting part 4 , also part 2 for predicting part 3 . The average velocity of part 1 and part 4 is less than average velocity in part2 and part3.

Acceleration is a good index for use by managers because they can know whether project progress has been slowed or accelerated. According to the physics laws, when velocity and acceleration have the same sign, the moving object movement has been accelerated. In project progress, the velocity is always positive, so when the acceleration is positive managers know that project progress has been expedited or when the acceleration is negative, the project progress has been delayed.

\section{Conclusion}

With the new method it is possible to forecast the future of the project, and also, find the final duration of the project by using physics rules. Equation path of the project progress shows the future status of the project in every period, and managers know how the project is proceeding and how it will be finished. This model also can do the performance evaluation of the project progress by comparing scheduled and actual, and its result is SRWI index that shows how the work is progressing in every period, and it's an excellent report for managers.

The new methodology is innovative and by using physics science in the control project the problem is being solved. The superiority of this method compared with the other methods is that this method is faster and it is also easier to use. Other methods are difficult and slow. By using complex models 
such as robust, fuzzy logic and Bayesian approach and also complex mathematical equations, those approaches can predict the final duration of the project. Furthermore, the cost and the time of implementing this new method is less than other methods. This method has some limitations; first limitation is for predicting the future of the project; predictors must be in the middle of the project, and it is not possible to forecast future in actual status before the middle of the project. The second limitation is if the project faces unforeseen changes in the future, the model cannot predict properly. For solving this issue, it is best to consider all the possible situations for the scenario. It should be noted that by considering some scenarios, the second limitation is solve correctly.

\section{References}

Bagherpour, M., Safari, M., \& Mohammad Sharifi, M. (2016). Applying mechanical equilibrium rules in project cost management. Proceedings of the Institution of Mechanical Engineers, Part B: Journal of Engineering Manufacture, 230(6), 1156-1163.

Caron, F., \& Ruggeri, F. (2016). Project Management in the Oil \& Gas Industry-A Bayesian Approach.

Caron, F., Ruggeri, F., \& Pierini, B. (2016). A Bayesian approach to improving estimate to complete. International Journal of Project Management, 34(8), 1687-1702.

Elshaer, R. (2013). Impact of sensitivity information on the prediction of project's duration using earned schedule method. International Journal of Project Management, 31(4), 579-588.

Kim, B. C., \& Reinschmidt, K. F. (2009). Probabilistic forecasting of project duration using Bayesian inference and the beta distribution. Journal of Construction Engineering and Management, 135(3), 178-186.

Li, J., Moselhi, O., \& Alkass, S. (2006). Forecasting project status by using fuzzy logic. Journal of construction engineering and management, 132(11), 1193-1202.

Hosseinian, S., \& Reinschmidt, K. F. (2015). Finding Best Model to Forecast Construction Duration of Road Tunnels with New Austrian Tunneling Method Using Bayesian Inference: Case Study of Niayesh Highway Tunnel in Iran. Transportation Research Record: Journal of the Transportation Research Board, (2522), 113-120.

Narbaev, T., \& De Marco, A. (2014). An earned schedule-based regression model to improve cost estimate at completion. International Journal of Project Management, 32(6), 1007-1018.

Pewdum, W., Rujirayanyong, T., \& Sooksatra, V. (2009). Forecasting final budget and duration of highway construction projects. Engineering, Construction and Architectural Management, 16(6), 544-557.

Vandevoorde, S., \& Vanhoucke, M. (2006). A comparison of different project duration forecasting methods using earned value metrics. International journal of project management, 24(4), 289302.

Vanhoucke, M., \& Vandevoorde, S. (2007). A simulation and evaluation of earned value metrics to forecast the project duration. Journal of the Operational Research Society, 58(10), 1361-1374.

Warburton, R. D., \& Cioffi, D. F. (2016). Estimating a project's earned and final duration. International Journal of Project Management, 34(8), 1493-1504.

Yousefi, N. (2018). Considering financial issues to estimate the project final cost in earned duration management. Iberoamerican Journal of Project Management, 9(2), 01-13.

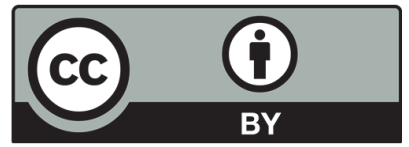

(C) 2019 by the authors; licensee Growing Science, Canada. This is an open access article distributed under the terms and conditions of the Creative Commons Attribution (CC-BY) license (http://creativecommons.org/licenses/by/4.0/). 